\title{
Application of distributed optical fibre for shallow foundation
}

\author{
Qurratu Aini Sirat ${ }^{1,}$ Dayangku Salma Awang Ismail ${ }^{1,2}$, Azman Kassim³, Ahmad Safuan A. \\ Rashid $^{3}$ \\ ${ }^{1}$ Postgraduade, Faculty of Civil Engineering, Universiti Teknologi Malaysia. 81310 Johor Bahru, Johor, \\ Malaysia \\ ${ }^{2}$ Lecturer, Faculty of Civil Engineering, Universiti Malaysia Sarawak, 943000 Kota Samarahan, \\ Sarawak, Malaysia \\ ${ }^{3}$ Assoc. Prof. Lecturer, Faculty of Civil Engineering, Universiti Teknologi Malaysia, 81310 Johor \\ Bahru, Johor, Malaysia
}

\begin{abstract}
Soil deformation is one of the major interests with regard to the stability analysis of the foundations. The deformations are signified for both vertical and lateral soil deformation; which the former plays vital role in designing a good foundation. As the stability of the foundation affect the stability of the entire structure, instrumentation and monitoring play an important roles in order to monitor the performances of the geotechnical structures. Until now the design of a foundation soil system is relied on the quantification of soil bearing capacity and foundation structural capacity and then followed by conventional monitoring system to observe the settlement so that within the allowable values. Therefore, this study focuses on the newly usage of distributed optical fibre sensing application to monitor strain distribution within a soil mass due to surcharge loading. It is expected to observe the strain distribution goes proportionally to vertical stress distribution concept; where higher strain measurement right below the loading position and decreases with depth. The advantage of distributed optical fibre sensing rather than conventional strain gauge is the sensor able to collect so-called average strain along the optical fibre compare to discrete measurement of strain gauge. This paper describes the experimental work conducted with the use of a distributed sensing technology named Brillouin Optical Time-Domain Analysis (BOTDA). A small scale of $1 \mathrm{G}$ model of a shallow foundation which represented by a load plate under incremental surcharge loading was stimulated to assess the soil mass deformation. The optical fibre were embedded in soil mass by layering in a horizontal direction which laid perpendicular to load direction. A comparison of numerical modeling using PLAXIS 2D and experimental works as part of this study. As a results, fibre optic is a good approach for instrumentations and monitoring for geotechnical structures as fibre optics is sensitive to the movement of the soil and fibre optic with anchorage system gave better strain measurement reading compare to without anchorage system.
\end{abstract}




\section{Introduction}

A foundation is part of a structure where it acts as a medium through which loads are transmits from the structure to the soil lying beneath. Foundation is characterized into two generic types which are shallow foundation and deep foundation. If competent founding strata are closed to the ground surface then shallow foundation should be considered, since they are relatively simple and cheap to construct. Shallow foundations are generally designed to satisfy both bearing capacity and settlement criteria as the stability of the foundations affects the stability of the entire building structure [1]. Both criteria were evaluated subjected to external load from the structure which utterly transferred the extra loads to the soil beneath a foundation. Therefore, understanding of stress transfer to the soil are equally important to settlement analysis for a foundation. As the normal stresses were understood to act proportionally with soil strain, the strain development in a soil mass were anticipated to follow the soil stress distribution for respective load types. Due to the limitations by conventional methods, optical fibre technology has been introduced in civil engineering monitoring system and among the first optical fibre sensor being used was Fibre Bragg Grating (FGB) technology. However, the problems with FBG is the ability to capture overall deformation of a geotechnical structure because of its point-wise measurement system. In order to observe the progression of soil deformation of a geotechnical structure, FBGs have to be positioned as many as possible onto the geo-structure so that a complete strain profile would be obtained and this would lead to uneconomic expenses for monitoring. [2] have discovered a new optical fibre sensor based on scattering light waves based on Brillouin interaction between the optical pulse and a counter-propagated continuous wave. They named the technique as Brillouin optical fibre time-domain analysis (BOTDA).

Last few decades, distributed optical fibre sensing technology technique has been applied to monitor the soil deformation. The aim of this study to assess the effectiveness of optical fibre sensing technology in strain response with loading in shallow foundation condition. A comparison was made in the experimental work through two types of arrangement (with anchor or without anchor on fibre optic) on the strain response. However, since the application of optical fibre sensing technology in geotechnical engineering as for assessment and monitoring tool has not truly developed and established, further comparisons have been made between fibre optic measurements in experimental work and numerical modelling. The numerical model is presumed to be a perfectly elasto-plastic model and it is estimated to produce a good result from the analysis. The differences of these two (2) methods; distributed optical fibre sensor and numerical simulation were made to conclude the hypothesis.

\section{Literature Review}

In designing any geotechnical engineering structures are often related to one these three general types of behaviour and properties such as deformation (compressibility), stability (strength) and seepage or groundwater flow (hydraulic conductivity) [3]. As for shallow foundation, stress exerted on the surface of the ground through foundation induced different ground movement or deformation. The deformation within soil mass best estimates through the computations of soil settlement [4]. The stress exerted on soil can be due to the soil own weight and also additional stress when it is loaded which also known as surcharge loading. In order to understand the process of the settlement, both physical modeling and numerical modeling are used.

As for physical method, laboratory tests of small-scale physical modeling which represent the real conditions of geotechnical structure often used as a methods to stimulate the soil behaviour since testing a full-scale foundation structure is costly, time-consuming and impossible to conduct [5]. There are four (4) types of physical model depending the size of 
the model: full-scale field tests, small-scale physical field tests, small-scale physical laboratory tests $(1 \mathrm{G})$ and lastly small-scale centrifuge tests. The small-scale physical model used to study the problems of geotechnical engineering because of its benefits in terms of size reduction, simplification and convenience, possible analysis for analytical models that are too complex and also the possible use of the laboratory data as for validation with theoretical and numerical methods [6].

Technically, the evaluation of physical modeling assisted with in-situ instrumentation and monitoring approaches. Instrumentation plays an important role in the assessment of behaviour of the soil. Back then, conventional methods had been widely used to monitor the performance of geotechnical structures. However, conventional methods such as inclinometers, Global Positioning System (GPS) and surveying techniques for measuring soil deformation limited in terms of either measurement range or accuracy[7][8]. Instrumentation with better range and accuracy give better data results as for design purposes. Besides, [7] also stated several inherent limitations when using the conventional instrumentation such as electromagnetic interference, a large number of cables of multipoint measurement, signal loss in long distance transmission and poor durability. Nowadays the fiber sensors technology is popular in geotechnical applications and far more promising due to its advantages of multiplexabilty, immunity to electromagnetic interference, high accuracy and good reliability [7]. Besides, the distributed optical fire sensing technology enable strain to be measured continuously along and optical fibre rather than discrete points.

However, the accuracy of fibre sensing technology is still a concerned point as the accuracy are depends on the interaction between the fibre optic and soil. The effectiveness of the fibre optic in measuring the strain depends on contact between the fibre optic and soil where a good contact is very crucial so that the correct amount of strain can measured by the fibre optic [9]. Besides, the poor quality sensor installation and temperature compensation are the probability factor of the uncertainties in the fibre optic measurements [8]. Thus, with the assistance of numerical method, the strain distribution within a soil mass can be obtained and validated by comparing the results with numerical simulation values.

\section{Methodology}

This part discusses and describes both experimental works and numerical modeling that have been conducted in order to achieve the objectives of the study. The experimental works further divided into four phases. First phase deals with the preparation of the optical fibre sensing cable. For second and third phase involved the preparation of small scale $1 \mathrm{G}$ model and installation of fibre optic in $1 \mathrm{G}$ model respectively. The final phase was the testing of $1 \mathrm{G}$ model under incremental loadings. As for numerical modeling, the model was simulated in PLAXIS 2D software where strain distribution were evaluated and then compared with experimental works results. The stimulation of numerical model has involved several steps as followed: 1) Creation of geometry, 2) Generation of finite element mesh, 3) Execution of finite element calculation, 4) The evaluation of the output results.

\subsection{Laboratory Works}

The effectiveness of optical fibre sensing technology from the soil-structure interaction for shallow foundation required a field tests. However, a testing in full-scale foundation is costly and time consuming and for these reasons, a small scale $1 \mathrm{G}$ model which represent the real structure was prepared and constructed. Figure 1(a) and 1(b) shows the chamber used and the dimension of the chamber for $1 \mathrm{G}$ model respectively. The soil used for this research study have been collected within the premises of Universiti Teknologi Malaysia (UTM), Johor 
Bahru campus which specifically from the area of P16 block located in the Faculty of Electrical Engineering.

The soil collected were subjected to laboratory testing such as Particle-Size Distribution tests, Atterberg Limit tests, Specific Gravity test, Compaction test and UnconsolidatedUndrained (UU) test in order to determine the properties of the soil. The Particle-Size Distribution tests (Sieve and Hydrometer test) were conducted to determine the soil classification based on soil's composition and gradation. The Atterberg Limits are the limits of water used to define soil consistency behaviour where it can be determined through Plastic Limit and Liquid Limit test. Specific Gravity test was conducted to calculate the specific gravity of soil where the knowledge of the specific gravity is required for the determination of voids ratio, porosity and degree of saturation of the soil. To determine the optimum moisture content during the compaction process as the soil achieve its maximum dry density, Proctor Compaction test are conducted whereas the shear strength of soil under undrained condition was evaluated from Unconsolidated-Undrained (UU) test. The results from these laboratory testing are shown in Table 1 then used as input parameters for small scale $1 \mathrm{G}$ model and also finite element analysis.

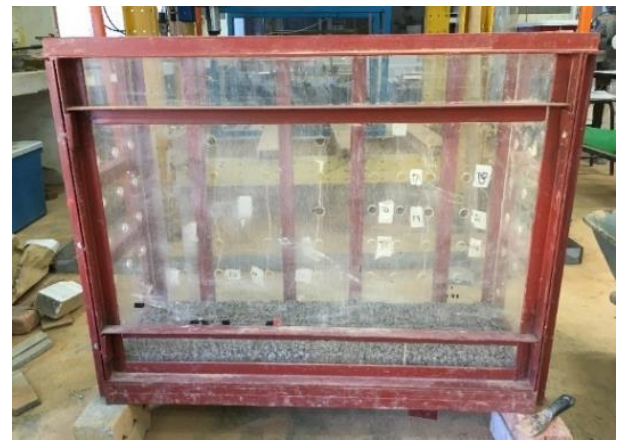

(a)

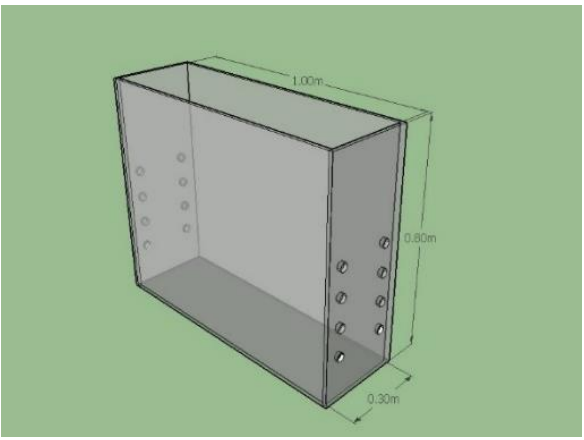

(b)

Fig. 1. (a) The Perspex chamber for $1 G$ Model (b) Dimension of the chamber.

Table 1. Summary of soil material properties.

\begin{tabular}{|l|c|}
\hline Description & Residual Soil \\
\hline Composition & Sandy Silt \\
Gravel (\%) & 0 \\
Sand (\%) & 31 \\
Silt (\%) & 40 \\
Clay (\%) & 29 \\
Liquid Limit, $w_{L}(\%)$ & 66 \\
Plastic Limit, $w_{p}(\%)$ & 48 \\
Plasticity Index $(P I)$ & 18 \\
\hline Specific Gravity, G & 2.607 \\
Bulk Density $\left(\mathrm{kN} / \mathrm{m}^{3}\right)$ & 17.77 \\
Dry Density $\left(\mathrm{kN} / \mathrm{m}^{3}\right)$ & 13.57 \\
Maximum Dry Density, MDD $\left(\mathrm{kN} / \mathrm{m}^{3)}\right.$ & 14.03 \\
Optimum Moisture Content, OMC $(\%)$ & 31 \\
Undrained Shear Strength, $\mathrm{C}_{\mathrm{u}}\left(\mathrm{kN} / \mathrm{m}^{2}\right)$ & 128.5 \\
\hline
\end{tabular}




\subsection{Testing on the Physical Modeling}

The soil was compacted into four (4) layers and the fibre optics were embedded in between the soil layers as for strain response for bottom, middle and top layer. Fibre optic layered horizontally which is perpendicular to the surcharge loading. During testing process, a small scale $1 \mathrm{G}$ model of shallow foundation which represented by a load plate test under incremental surcharge loading was stimulated to evaluate the performance of soil. The size of plate with $300 \mathrm{~mm}$ width and $150 \mathrm{~mm}$ length. The optical connecters were connected to the BOTDA analyser which also known as Distributed Strain and Temperature Sensor (DSTS). DSTS is a sophisticated fibre optics sensor system which used the Brillouin scattering in optical fibres to measure relative changes in both strain and temperature along the length of fibre optic. Relative Strain mode used at this present research. The measurement of fibre optic were taken by using DSTS while exerting a pressure on the plate load. The result obtained were the response of strain distribution measured by the fibre optic that embedded within the soils.

\subsection{Finite Element Analysis}

As for numerical analysis, the physical modeling then modelled in the PLAXIS 2D software and continuous strain distribution evaluated and compared with the strain measurement obtained from the $1 \mathrm{G}$ model. Plane-strain model type was used to model the $1 \mathrm{G}$ model. Besides, before a calculation in Staged construction can be made, material data sets had to be assigned to all soil volumes and structures. A suitable material model and appropriate material parameters need to be assigned to the geometry in order to stimulate the real behaviour of the soil and for this research, Mohr-Coulomb model was selected to define the shear strength of soils and all the parameters were entered according to Table 2.

Table 2. Material Properties of Soil.

\begin{tabular}{|l|c|c|c|}
\hline Parameter & Name & Sandy Silt & Unit \\
\hline General & Model & Mohr-Coulomb & - \\
\hline Material Model & Type & Undrained $(\mathrm{C})$ & - \\
\hline Drainage Type & $\Upsilon_{\text {unsat }}$ & 17.77 & $\mathrm{kN} / \mathrm{m}^{3}$ \\
\hline Unit weight above phreatic level & $\mathrm{E}_{\mathrm{u}}$ & 7500 & $\mathrm{kN} / \mathrm{m}^{2}$ \\
\hline Parameters & $v_{\mathrm{u}}(\mathrm{nu})$ & 0.33 & - \\
\hline Young's Modulus & $\mathrm{S}_{\mathrm{u}, \mathrm{ref}}$ & 128.5 & $\mathrm{kN} / \mathrm{m}^{2}$ \\
\hline Poisson's Ratio & $\varphi_{\mathrm{u}}$ & 0.00 & ${ }^{\circ}$ \\
\hline Undrained Shear Strength & $\psi$ & 0.00 & \\
\hline Friction Angle & & \\
\hline Dilatancy Angle &
\end{tabular}

Shallow foundation was created in the Structures mode of the program using Create Line Load features. The input value of the distributed load were 1.0 to $15.0 \mathrm{kN} / \mathrm{m}^{2}$ in the $\mathrm{y}$ direction. The finite element model (1G Model) was completed once the mesh had been generated. Staged construction mode was clicked to proceed with the execution of a finite element calculation phases. There were two (2) phases executed for the soil model: Initial phase and Footing phase. In Initial phase, all the structural elements and loads that were presented in the geometry were initially switched off and only the soil volumes and initial conditions of the soil model was activated. The construction of the footing was done in a 
separate calculation phase (Footing Phase). In this phase, the plate and the line loads were activated. The Calculate button at the side tool bar was clicked to start the calculation process. As the calculation phase had completed, the results were displayed in the Output program. Finally, the incremental strain was selected from Deformations drop down menu to evaluate the strain distribution in the soil mass and the results will be further discussed the next chapter.

\section{Results and Discussion}

\subsection{Fujikura 12-ribbon Optical Fibre Strain Distribution}

Brillouin monitoring systems are generally used for measuring changes in strain or temperature. However, it cannot directly measured the strain and temperature as all the data obtained from BOTDA Analyser were in terms of optical fibre length and frequency distribution. Thus, the measured data were compared with the baseline and the difference between the two data frequency were converted into strain by multiplying the results with fibre strain coefficient [20 $\mu \varepsilon / \mathrm{MHz}$ ]. Baseline which is the original Brillouin frequency distribution will be used as a standard to which other measurement will be compared. The surcharge loading exerted during the plate load test were $1 \mathrm{kN}, 3 \mathrm{kN}, 5 \mathrm{kN}, 7 \mathrm{kN}, 9 \mathrm{kN}, 12 \mathrm{kN}$, $13 \mathrm{kN}, 14 \mathrm{kN}$ and $15 \mathrm{kN}$. The testing were conducted in step loading where the exerted pressure stop as the data were taken at each mentioned loading. However, the surcharge loading was stopped at $15 \mathrm{kN}$ since the frequency distribution showed unusual pattern in the BODTA Analyser as the soil start to fail at $15 \mathrm{kN}$ load.

A graph for strain distribution against optical fibre length for each load were tabulated as shown in Figure 2. Since Fujikura 12-ribbon optical fibre used only to measure changes in strain or temperature, thus all the data presented in this paper would be in strain distribution. The total length of the fibre optic was $21 \mathrm{~m}$ yet from the graph below, it shows only distribution of strain from $4 \mathrm{~m}$ to $17 \mathrm{~m}$ as the fibre optic was embedded within the soil mass from $5 \mathrm{~m}$ to $16 \mathrm{~m}$ length fibre but adding $1 \mathrm{~m}$ extra before and after for graph purposes. From Figure 2, it shows that $15 \mathrm{kN}$ surcharge load gave higher strain distribution compared to the rest of the surcharge loading. The higher the surcharge load applied to the soil mass, the higher the strain values.as higher loads mean higher forces acting on the soil which results in higher deformations within the soil mass and lead to higher strain values. 


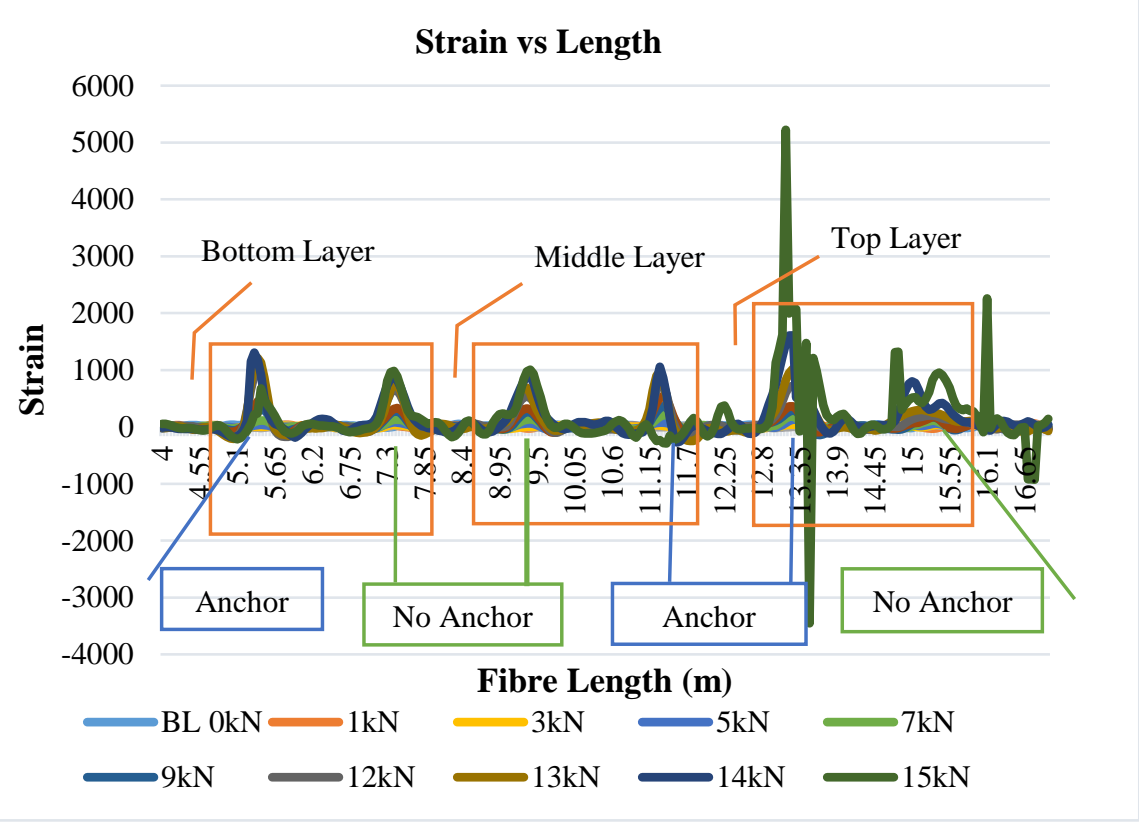

Fig. 2. Strain vs Fibre Length Graph.

Figure 2 also depicts the value of strain for bottom, middle and top layer of soil when undergoes certain loading during load test. There are two peaks of graph for each soil layer where one peak represents fibre optic with anchor and the other peak as for fibre optic with no anchor and their position also shown in the Figure 2. The positioned of the fibre optic for both anchor and no anchor were alternate starting from bottom layer to towards top soil layer due to the installation techniques of fibre within the chamber and the comparison of strain measurement between them will be discussed in the next sub-chapter.

\subsection{Fibre Optic-Soil Interaction}

The results of an anchor fibre optic and non-anchor fibre for top, middle and bottom layer are shown in Figure 3, Figure 4 and Figure 5 respectively. These two methods of fibre optic implemented in this study to help with the understanding of the interaction between optical fibre and soil mass. 


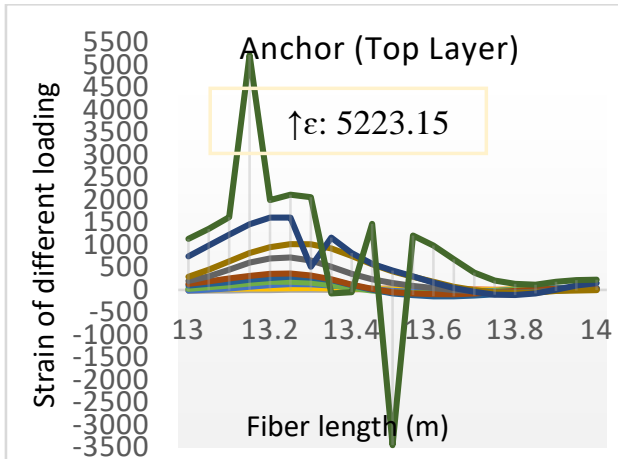

(a)

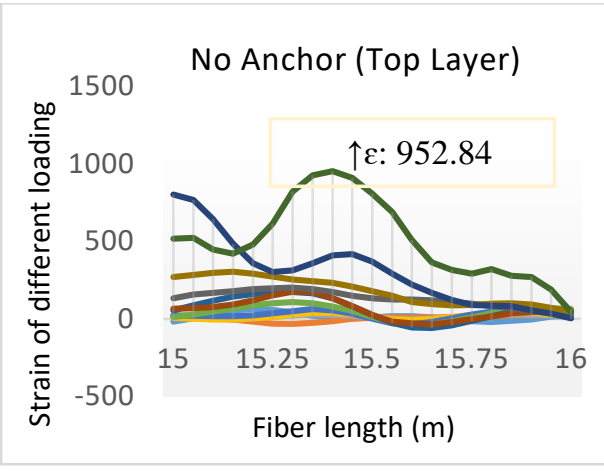

(b)

Fig. 3. Strain distribution on top layer (a) anchor (b) non-anchor fibre optic.

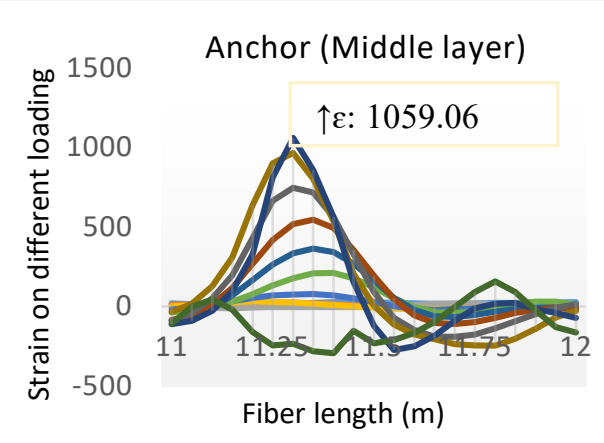

(a)

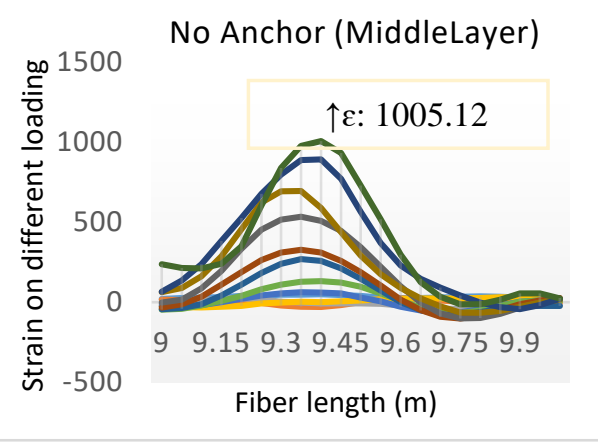

(b)

Fig. 4. Strain distribution middle layer (a) anchor (b) non-anchor fibre optic.

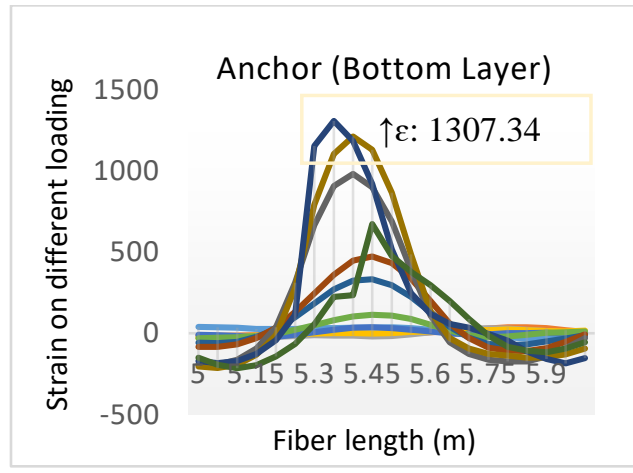

(a)

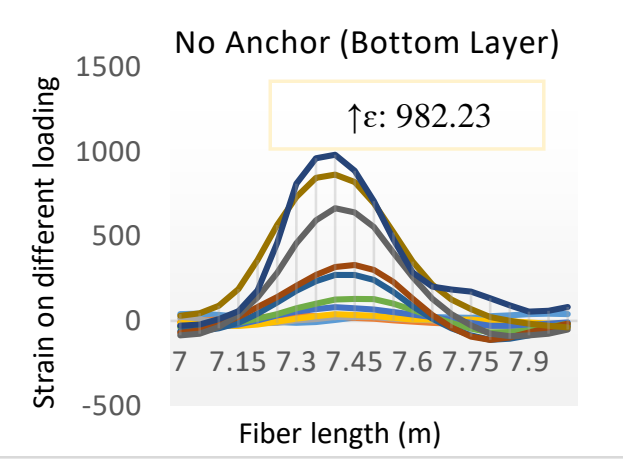

(b)

Fig. 5. Strain distribution on bottom layer (a) anchor (b) non-anchor fibre optic.

From an overall view, both results for anchor and non-anchor attachment methods shows that fibre optic is sensitive to the surrounding ground movements where it can measured up to micro strains $(\mu \varepsilon)$ and the strain values for fibre optic with anchor are slightly higher than non-anchor fibre optic. Hence, the anchorage method give better strain results. 
[10] claim that the integration method implemented in their study with regards to the integration of the fibre into the structure and ground proved to be feasible and produced good results. Both anchor and non-anchor fibre optic are sensitive to the ground movements however, fibre optic with anchor is more sensitive and efficient since it have higher strain values which the results of better interaction between optical fibre and soil. Then, the results of anchored fibre optic are used and compared with finite element analysis since it is more efficient and gives better strain distribution profile.

\subsection{Comparison with PLAXIS 2D}

In order to verify the effectiveness of optical fibre sensing technology, the validity of the fibre optic measurements are compared with PLAXIS 2D. Incremental volumetric strain $\left(\Delta \varepsilon_{\mathrm{v}}\right)$ for each distributed load are evaluated and compared with anchor fibre optic result. Cross section features on the side of tool bar was used to evaluate the strain distribution for bottom, middle and top soil layer within the soil mass. The differences in strain distribution between optical fibre sensing and PLAXIS 2D are shown in Figure 6, 7, 8, 9, 10, 11, 12, and Figure 13.

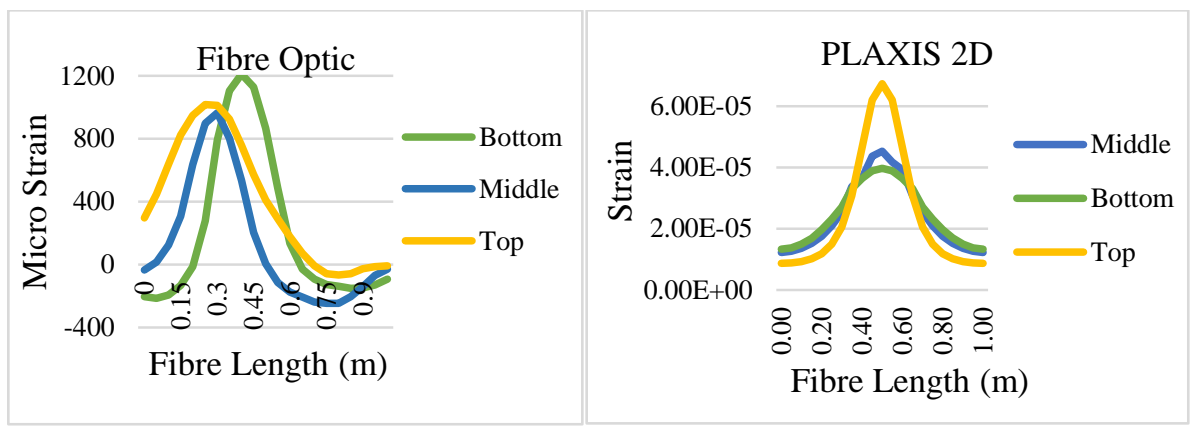

Fig. 6. Strain distribution for bottom, middle and top layer due to $1 \mathrm{kN}$.

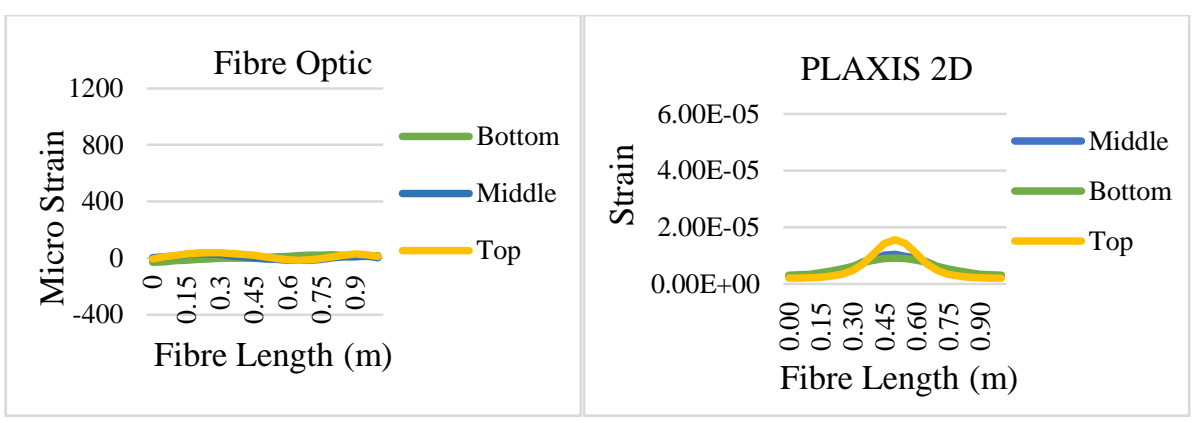

Fig. 7. Strain distribution for bottom, middle and top layer due to $3 \mathrm{kN}$. 


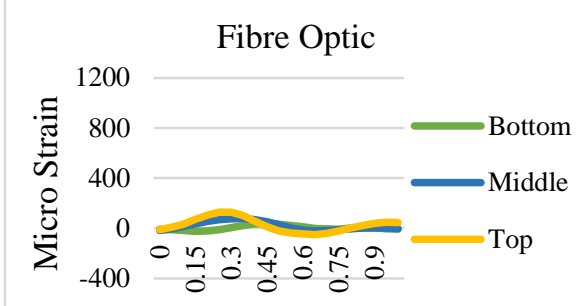

Fibre Length (m)

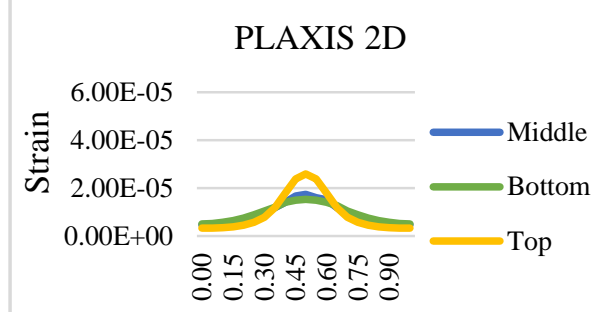

Fibre Length (m)

Fig. 8. Strain distribution for bottom, middle and top layer due to $5 \mathrm{kN}$.

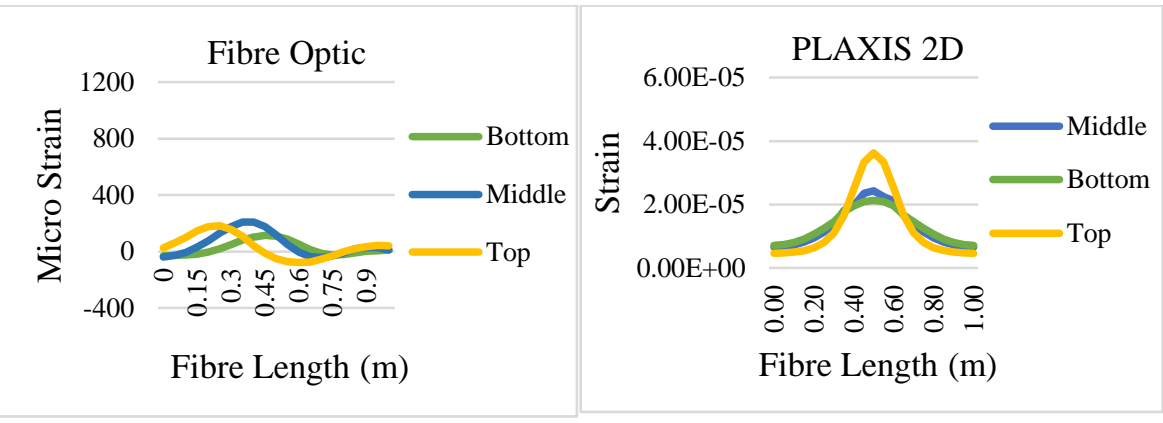

Fig. 9. Strain distribution for bottom, middle and top layer due to $7 \mathrm{kN}$.

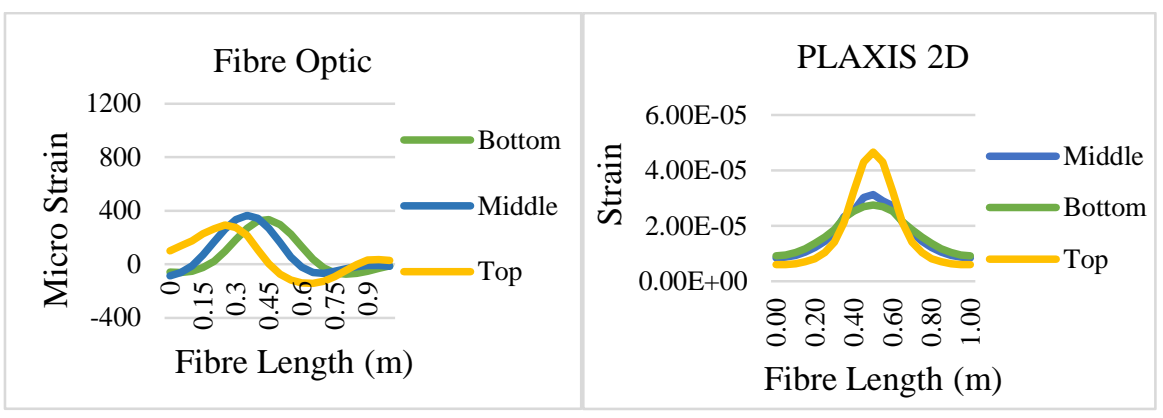

Fig. 10. Strain distribution for bottom, middle and top layer due to $9 \mathrm{kN}$.

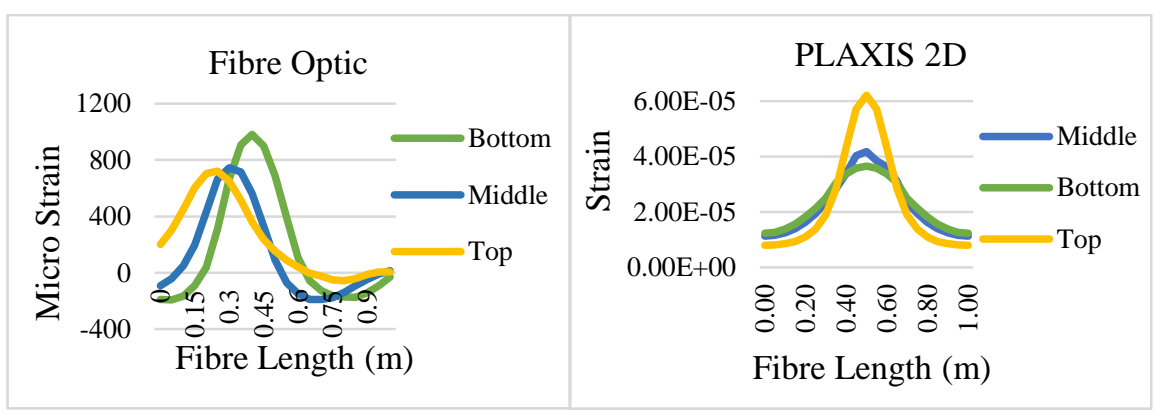

Fig. 11. Strain distribution for bottom, middle and top layer due to $12 \mathrm{kN}$. 


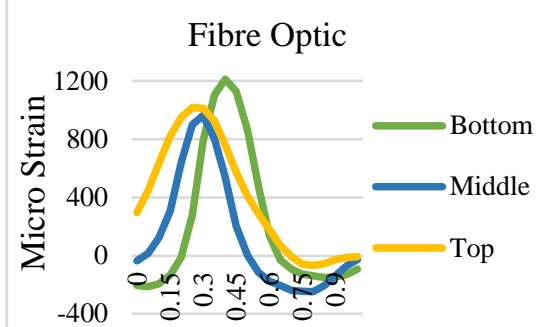

Fibre Length (m)

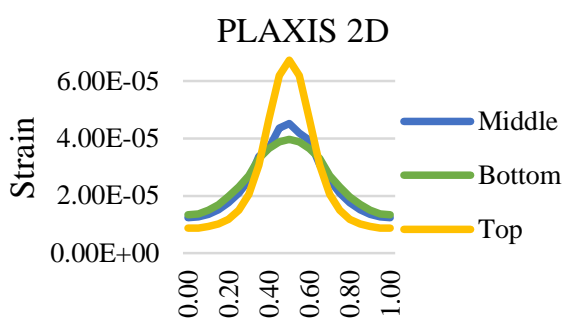

Fibre Length (m)

Fig. 12. Strain distribution for bottom, middle and top layer due to $13 \mathrm{kN}$.
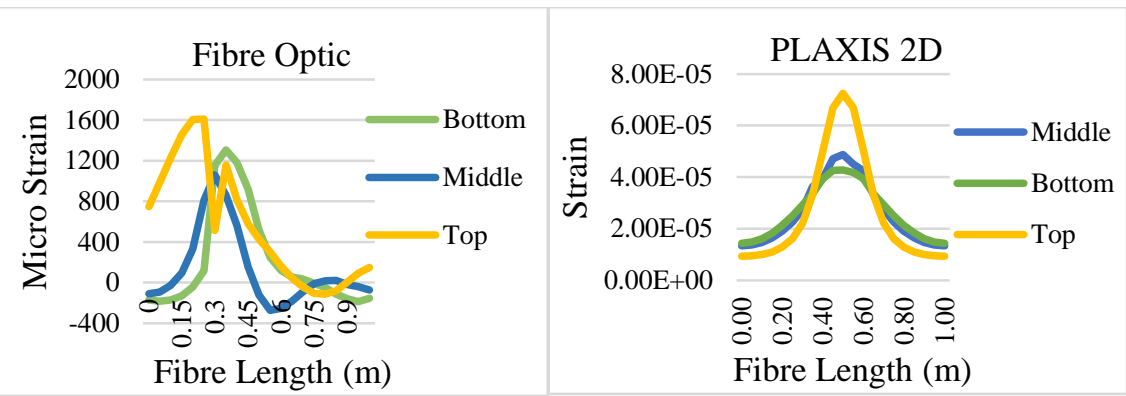

Fig. 13. Strain distribution for bottom, middle and top layer due to $14 \mathrm{kN}$.

From all the results above, there are slight difference in strain measurement values for both fibre optic and PLAXIS 2D where fibre optic give higher strain values compared to PLAXIS 2D for all the surcharge loads. However, there are not much difference in the strain values. Whereas, in terms of strain distribution, PLAXIS 2D shows a consistent pattern of strain where top soil layer gives the highest value of strain gradually decreasing with depth. Theoretically, soil deformations will be higher at the top of the soil layer as it located near to the surcharge loading. Hence, the measurement of distributed strain value will be higher at the top soil and eventually decreases with depth as illustrated by PLAXIS 2D. However, the strain distribution illustrated by fibre optic somehow give a different pattern if compared to PLAXIS 2D. For $1 \mathrm{kN}$, the bottom layer give highest strain value compared to other soil layer. But at $3 \mathrm{kN}$ and $5 \mathrm{kN}$, the top layer give the highest strain value where it have the same pattern in PLAXIS 2D. The pattern change as for $7 \mathrm{kN}$ and $9 \mathrm{kN}$ surcharge loading where the middle soil layer shows highest strain value and the pattern change again for $12 \mathrm{kN}$ and $13 \mathrm{kN}$ where the bottom layer give highest strain value. The results discrepancy can be due to many factors and yet the interaction between optical fibre and soil can has been considered to be a dominant factor

During $14 \mathrm{kN}$ and $15 \mathrm{kN}$, the top soil layer shows unusual peak at some points from the distributed graph and there are big difference in the strain values especially on top of the soil layer. Slippage of fibre might occurred or some of the anchor restrict the movement of fibre optic which lead to a high tensile stress for fibre optic under high surcharge loading condition. At this point, the anchor has no function and no good data obtained after $15 \mathrm{kN}$ of loading. 


\section{Conclusion}

As a conclusions, fibre optic is a good approaches for instrumentations and monitoring for geotechnical structures since numerical modeling can validate the effectiveness of fibre optic as there are not much difference in the strain values. Fibre optic are very sensitive to the movement of the soil where it can measure up to micro strain $(\mu \varepsilon)$ and the anchorage methods give a better strain measurement. Besides, optical fibre is inexpensive and able to measure strain along an optical fibre rather than discrete points.

The authors would like to acknowledge the support of the Universiti Teknologi Malaysia and the Ministry of Higher Education Malaysia through the awarded Research University Grant (RUG), vote number $11 \mathrm{H} 04$ are highly appreciated.

\section{References}

1. B. Das and N. Sivakugan, "Settlements of shallow foundations on granular soil an overview," Int. J. Geotech. Eng., vol. 1, no. 1, pp. 19-29, 2007.

2. T. Horiguchi and M. Tateda, "BOTDA - Nondestructive measurement of singlemode optical fiber attenuation characteristics using Brillouin interaction: Theory," $J$. Light. Technol., vol. 7, no. 8, pp. 1170-1176, 1989.

3. S. L. Barbour and J. Krahn, "Numerical Modelling - Prediction or Process ?," Geotechnical News, vol. 22, no. December. pp. 44-52, 2004.

4. M. Mardia, "Finite Element Analysis of Elastic Settlement of Shallow Foundation Finite Element Analysis of Elastic," Ph.D. dissertation, Dept. of Civil Eng., Bangladesh University of Engineering and Technology, 2014.

5. A. Altaee and B. H. Fellenius, "Physical modeling in sand," Canadian Geotechnical Journal, vol. 31, no. 3. pp. 420-431, 1994.

6. M. Al Heib, F. HdrEmeriault, M. Caudron, L. Nghiem, and B. Hor, "Large-scale soil - structure physical model ( $1 \mathrm{~g}$ ) - assessment of structure damages," Int. J. Phys. Model. Geotech., vol. 13, no. 4, pp. 138-152, 2013.

7. H.-F. Pei, J. Teng, J.-H. Yin, and R. Chen, "A review of previous studies on the applications of optical fiber sensors in geotechnical health monitoring," Measurement, vol. 58, pp. 207-214, 2014.

8. C. C. Zhang, H. H. Zhu, and B. Shi, "Role of the interface between distributed fibre optic strain sensor and soil in ground deformation measurement," Sci. Rep., vol. 6, no. October, pp. 1-9, 2016.

9. H. Mohamad, "Distributed Optical Fibre Strain Sensing of Geotechnical Structures," Ph.D. dissertation, Dept. of Eng., University of Cambridge, 2008.

10. M. Iten, A. M. Puzrin, and A. Schmid, "Landslide monitoring using a road-embedded optical fiber sensor," no. June 2014, p. 693315, 2008. 